\section{Examining the critical role of education psychology in teacher education: Circumventing professional misalliance in teacher training institutions in Uganda}

\author{
Pontian, Kabeera $\bowtie$ \\ Victoria University, Uganda (pontiankbr@gmail.com)
}

Received: 13 September 2021

Revised: 17 September 2021 DOI: $10.5861 /$ ijrse.2021.a081

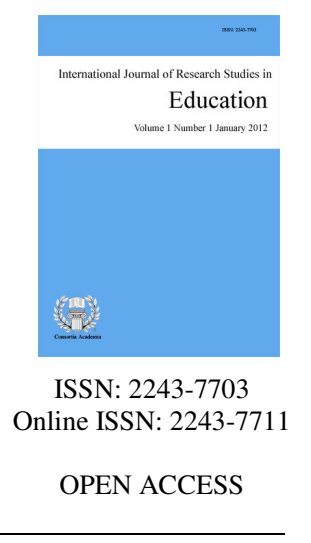

\title{
Abstract
}

The study highlights that Education without psychology is inconsequential and can hardly be significant to both the individual and society. The study observed that mutual dependency on education psychology in teacher education training is a significant concept for an effective teacher training process. The study discovered that the contemporary education has introduced new education concepts like psychology which has transformed education fortitude and bestowed another implication to teacher educators and debunked the old discriminative system which defined students' abilities based on their social class. The study further discovered that human beings can differ in terms of their mental abilities but all have the potential to learn. In this regards, education psychology orients the teachers into a comprehensive human state which involves the mind among other things. The study establishes that education psychology is essential for teacher trainees since learning hinges more on students' mental abilities. Moreover, Educational Psychology gives hand to teachers in managing the status quo, it gives room to teachers to understand what makes the teaching more relevant, what to teach and how to teach it. Hence it is through education psychology that teachers are able to meet the 21 st century contentment in as far as nurturing a competent human labor-force is concerned. In raising alarm, criticizing the status quo, and making recommendations, various study groups and blue ribbon panels have focused on economic issues, equity and excellence, the need for more rigorous subject matter preparation, and on the restructuring of incentives are the career ladder for teachers.

Keywords: education psychology, teacher Education, Uganda 


\section{Examining the critical role of education psychology in teacher education: Circumventing professional misalliance in teacher training institutions in Uganda}

\section{Introduction}

The notion " teacher education" has seen a glut of prose that has fully concurred with a general accord of what makes a "good" teacher training and preparation (Smith, 2005). Since valuable teacher training slots in a profusion of content knowledge, pedagogical and didactical methodologies to make learning and teaching more relevant and meaning. Moreover, meaningful teacher training slots in an assortment of subject matter as well as the knowledge content with a far-reaching understanding of learning styles and methods and how all these translates into knowledge. Valuable instructional technique in the process of developing abilities in the learners coupled with nurturing unique citizenry (Darling-Hammond, 2006; Kennedy, 2005; Korthagen, 2004). In this respect, mirror image and individual examination are recommendable components of professional and competent teacher education and the sense in which they execute their duties to meet the obligatory professional demeanor (Darling-Hammond, 2006; Labrie, Brdarevic, \& Russell, 2000; Smith \& Van der Westhuizen, 2000). With such an assortment of indispensable teacher skills "there is a budding compromise that the quality of the teacher poses a momentous variation in way the students learn as well as the overall school effectiveness" (Cochrane-Smith \& Zeichner, 2005, p. 40). The way the students perform may be indicate or define the worthiness of the teacher and their level of qualification. Cochrane-Smith and Zeichner argue that the characteristics of teacher preparation that most effect student achievement should be identified and policies need to be tailored towards this

\subsection{Background}

Human capital theory concedes that education is an investment with clear lenses for the future. The assertion is however true only when serious considerations are taken in the process of investing in the future through building human capital. In this respect all component of human growth and development must be addressed significantly for this investment to be relevant thus the birth of psychology in education. Over the years, psychology in education has been a serious component of teacher training right transcending from showpieces in multitudes of programs and all the way to the period when it was considered irrelevant until now when it is viewed with an eye of messiah ship towards quality teacher training and teaching. Today, psychological knowledge is used to make and affirm policy reforms both in teaching and schooling. Today's standards for teacher qualification stipulates that teachers will have a deeper understanding on what influences effective teaching and learning, be able to develop teaching technique that triggers students' individual development, motivation as well as developing the understanding of the existing individual differences. Moreover, this article centers on themes that delves more on issues of reforms and raising teacher standards as well as placing making learning a primary element in the process of drafting these reforms as well as integrating studies all together to make learning more meaningful.

Making learning the fulcrum of teaching as well as incorporating the general studies coupled with the significance of collaborations with other public institutions. Schools can even give birth to mixed implications which can be negative or positive towards the position of psychology as a discipline for teacher education hence quality teachers for quality human resource empowerment. Traditional models of teacher training often emphasize the pedagogy above content area preparations and critics of this school of thought advances that this model is so significant since it harnesses all the primary areas towards teacher training and one key model of this teacher reform according to (Shulman, 1987). This model defines teacher proficiency as a component that is comprised of three key elements such as content knowledge, Pedagogical knowledge, knowledge of learners and learning. In this regard, the first strand has been the focus of several critiques and subsequent revisions of teacher training programs. The second strand represents the traditional focus of teacher preparation programs, methods 
instruction. The third strand, however, has received relatively little attention in the recent reform literature. We propose that what is needed is a model for preparing teachers which includes as a key component a strong focus on expertise in diagnosing human learning, motivation, and development. We wish to note, to avoid misunderstanding, that we are not dismissing the importance of either pedagogical or content preparation. Such a recommendation would be unsound. Nevertheless, turning teachers into skilled diagnosticians of learners and learning, we argue, is an essential ingredient in upgrading teacher preparation and professional development. Hence, our approach is not so much a matter of replacing current reforms as it is a matter of completing them. Promoting the development of diagnostic expertise with regard to learning/cognition, motivation, and development is, we believe, the critical missing element in typical teacher preparation programs.

\section{Review of literature}

It is indeed a common understanding that teachers should have a considerable knowledge on the concept of human development given the urgency of their profession. In this respect theories of learning and motivation have been highly regarded many years. All programs and courses regarding this topic have been at the helm of teacher training programs for over 100 years (Berliner, 1993). It is however unfortunate that these courses given the sense in which they are taught today have lost the touch on which they were founded. They rarely produce much beyond a rudimentary understanding of their core content. Generally, they are they are predominantly educational information as possible in the shortest amount of time. Surprisingly the relevance of education psychology has been confronted of-recent and no longer has a serious point of reference in teacher training program (Anderson et al., 1995; Berliner, 1993; Hoy-Wool folk, 2000; O'Donnell \& Levin, 2001; Weinstein \& Way, 2003). Actually the significance that was formerly attached to education psychology has become surplus to requirement and it is now a taken for granted course and thus education psychology finds its self at the crossroads with few ready to defend the inclusion of its contents in teacher education programs (Anderson, et. al., 1995; Weinstein \& Way, 2003).

There have been valid discourses over the significances of education psychology and how momentous it can turn out to be for better teacher training, Anderson et al., 1995; Hoy-Woolfolk, 2000; Poulou, 2005; Renninger, 1996; Shuell, 1996). Much it is considered germane towards over development, such has at the same time been challenged (Doyle \& Carter, 1996). According to Doyle and Carter (1996, p. 25). It should be noted that some scholars do not buy into the idea of teaching education psychology effectively; just like Doyle and Carter emphasize that education psychology should be taught with a primary purpose of contributing to teacher training methods of instruction. Much as we cannot refute the fact that education psychology can add knowledge on the method of teacher training instruction. It however has little implication on the general contribution of education psychology to teacher training and preparation and professionalization. Doyle and Carter emphasize the type of knowledge that is not purely germane in the training and teachers' professional development. The knowledge advanced here chiefly procedural and tacit in nature and does not suit the development of the kinds of reflective engagement with practice that will lead to generalize and flexible principles of practice needed for today's professional educators.

Instead, what is needed is a solid grounding in knowledge of learners and learning (development, cognition, motivation, etc.) coupled with extensive and penetrating practice in the application of such knowledge via diagnosis of learners and learning situations. The question remains, however, how is this to be accomplished? One approach that has been widely recommended in reform proposals for educational psychology involves the use of rich cases from educational settings to situate and apply the theoretical concepts taught in an educational psychology course (Anderson, et al. 1995, Hoy-Woolfolk, 2000; Renninger, 1996). Another important device is the use of tutoring by teacher candidates as an opportunity to develop diagnostic skill (Renninger, 1996). By situating the teaching of theoretical knowledge of cognition, development, and motivation in discussion of case exemplars and tutoring conditions, teacher education candidates can be taught that such content represents a set of useful tools for the diagnosis of learners and learning, both of the general and content specific variety. Furthermore, within such a process they can be prompted to develop and hone analytical skills not typically 
Pontian, K.

emphasized in teacher preparation programs.

\section{Findings and Discussion}

\subsection{Knowledge and learning: an element of education psychology}

Phenomenological researchers from across all disciplines have all agreed on the assertion that knowledge is not given it is instead constructed. Moreover, this knowledge is acquired through the continuous interactions between the teachers and the students. In fact Carnegie Forum Task Force and the Holmes Group have recently highlighted on the new vision of informant teachers and they explain that teachers who are constantly engaged in the learning process should be able to learn all the time.

The study establishes that society needs to be oriented about learning that dates back in the days even before classroom sort of arrangement for learning was born, there were well organized manner in which learning took place hence the existence of sages we worship today. Teachers must be willing to learn, moreover the content that add value and significant to those they are teaching. Learning cut be taken as short term engagement, learning and development are life long process for both the teachers and the students. For some time now the education psychology has been hugely confronted by several advances in cognitive psychology. It is imperative to note that the field of developmental psychology has been transformed in recent years by a life-span developmental perspective that argues for a view of teachers as professionals who continue to learn and develop throughout their teaching careers. In developing this capacity for continuous learning, teachers may benefit by knowing not only something about how other teachers learn, but also by reflecting on their own processes of earning.

For the matter two important paradigms have been adequately analyzed to be able all concerns to do with the content for education psychology, it is important to consider the significance of Meta cognitive for classroom teaching and Meta cognitive knowledge for classroom learning. It is essential that a teacher understands these concepts through education psychology so that he or she can be able to have the ability and the awareness to diagnose and understand the students cognitive level as well as reflecting on the best principles and strategies for teaching whichever class and at any level. In the same way, Meta cognitive knowledge for classroom learning the former involves learners' self-awareness of their own cognitions through which they acquire information, gain understanding, and learn in the classroom. Although little research has been done on such met cognitive knowledge of teachers, many researchers, including educational psychologists, are now suggesting that teachers' self-awareness and deliberate action are important aspects of teaching expertise that need to be studied.

\subsection{Teacher's willingness to learn and the new realm of education psychology}

Numerous studies have been carried-out and try to lay into the new domain of knowledge in education psychology which is the psychology of learning and thinking. Much as this call had been tabled for many decades ago but the study found-out that the concept of teacher learning has not been fully given attention by education researchers and psychologist and the failure to address this could have a negative bearing on the entire teaching profession and both cognitive and teacher professional development will continuously be put to test. For years, education psychology has not taken teacher learning as a major area of study given its primary importance in children's learning and their cognitive development. In fact, this argument resonates with Leinhardt and Putnam and very pronounced in their research on the networks of teachers' knowledge and script theory. They post that the role of teachers' understanding of subject matter and interpretation of what students' mean are most prominent in the teaching and learning process. It is in this respect that people gain an understanding on why teachers behave the way they do and so does that students. These scholars have therefore managed to explore and come up with new findings on what influences teachers to think in any way they do, their plans and what influences their plans and how teachers work is constrained by the world in which they operate from. 
Taking the psychological stance to understand what influences teachers to behave in any way they do draws the researchers very closer to the teachers and by so doing, essential knowledge is constructed out of such discourses on how teachers think, plan and even decide in any way that influences their teaching practices and other professional engagements. Such psychological implications windows into teachers' thinking or psychological lenses for examining teaching also open up new possibilities for metaphors that convey new ways of thinking about how to connect psychology to teacher education. In fact, few scholars have taken serious consideration over teachers thinking and their knowledge from a longitudinal point of view, many have taken a cross sectional approach to understanding teachers thinking and their knowledge and thus they have not been able to define teachers learning as well as the development of teachers thinking over time. Until recently that education psychologist and teacher educators begun working together to conduct a longitudinal study. The study discovered that it is until recently that scholars in the field of education psychology and teacher educators decided to work together and carryout longitudinal surveys on how teachers learn to teach, the materials to use while conducting teaching among others. They have conducted several studies in pursuit of teacher development knowledge, skills and the temperament related to teaching and learning. This group of scholars is basically examining teachers' beliefs and attitudes including the conceptions of knowledge. It is from this background that the basis of is paper is founded with a primary aim of highlighting the various efforts made by education psychology researcher and teacher educators to justify the need for new approach towards education psychology for teacher training. The above findings clearly justify the need for education psychology content in the entire teaching and learning processes.

Since both researchers are conducting studies on teachers' thinking and on teachers' learning which are quite recent, yet little of the content on these two significant areas in teaching and learning has been worked on and appeared relevant in today's education psychology books. Much as little content about education psychology has been written down in text books, this review paper proposes that education psychology is important towards teacher training and must be highly considered for future teacher professional to be relied on for better human and cognitive development of children. Knowledge of the psychology of teachers' learning might contribute to the effective teaching of educational psychology in two ways. First, such knowledge would be useful as educational psychologists begin the process of conceptualizing the learning and teaching of educational psychology in the preparation of teachers for the 21st century. Such knowledge would be particularly informative as educational psychologists think about the possibility of adapting the content and methods of educational psychology to the individual learner

\section{Conclusion}

In winding up the review this review paper, the findings indicate the significance of psychology to teacher training and the learning process. The above discussion illustrates the centrality of knowledge of psychology to teachers' educators. The study therefore proposes three points for consideration: first, that the psychology in teacher constitutes an important new domain of knowledge in educational psychology; second, that the knowledge of theories and research findings on the psychology in teacher education may be meaningful and important for students in teacher education, and further may enhance their teaching practice as well as enhancing the abilities of ability of education faculties to teach educational psychology more effectively more so during teacher preparation programs. Finally, as mentioned, it would lead to more effective practice in the classroom.

\section{References}

Anderson, L. M., et al. (1995). Educational psychology for teachers: Reforming our courses, rethinking our roles. Educational Psychologist, 30(3), 143-157. https://doi.org/10.1207/s15326985ep3003_5

Berliner, D. C. (1993). The 100-year journey of educational psychology: from interest, to disdain, to respect for practice. In T. F. Fagan \& G. R. Vanden Bos (Eds.), Exploring applied psychology: Origins and critical analyses. Washington, DC: American Psychological Association.

Doyle, W., \& Carter, K. (1996). Educational psychology and the education of teachers: A reaction. Educational 
Pontian, K.

Psychologist, 31(1), 23-28. https://doi.org/10.1207/s15326985ep3101_3

Hoy-Woolfolk, A. (2000). Educational psychology in teacher education. Educational Psychologist, 35(4), 257-270. https://doi.org/10.1207/S15326985EP3504_04

O'Donnell, A. M. \& Levin, J. R. (2001). Educational psychology's healthy growing pains. Educational Psychologist, 36(2), 73-82. https://doi.org/10.1207/S15326985EP3602_2

Poulou, M. (2005). Educational psychology within teacher education. Teachers and Teaching: Theory and Practice, 11(6), 555-574.

Renninger, K. A. (1996). Learning as the focus of the educational psychology course. Educational Psychologist, 31(1), 63-76.

Shuell, T. J. (1996). The role of educational psychology in the preparation of teachers. Educational Psychologist, $31(1), 5-14$.

Shulman, L. S. (1987). Knowledge and teaching: Foundations of the new reform. Harvard Educational Review, 57(1), 1-23.

Weinstein, C. E., \& Way, P. J. (2003). Educational psychology. In D. K. Freedheim (Ed.), Handbook of psychology (Vol. 1). History of psychology. NY: John Wiley \& Sons. https://doi.org/10.1002/0471264385.wei0113 